\title{
Consciously Controlled Breathing Decreases the High-Frequency Component of Heart Rate Variability by Inhibiting Cardiac Parasympathetic Nerve Activity
}

\author{
Konosuke Sasaki ${ }^{1}$ and Ryoko Maruyama ${ }^{1}$ \\ ${ }^{1}$ Department of Health Sciences, Tohoku University Graduate School of Medicine, Sendai, Miyagi, Japan
}

\begin{abstract}
Heart rate variability (HRV), the beat-to-beat alterations in heart rate, comprises sympathetic and parasympathetic nerve activities of the heart. HRV analysis is used to quantify cardiac autonomic regulation. Since respiration could be a confounding factor in HRV evaluation, some studies recommend consciously controlled breathing to standardize the method. However, it remains unclear whether controlled breathing affects HRV measurement. We compared the effects of controlled breathing on HRV with those of spontaneous breathing. In 20 healthy volunteers, we measured respiratory frequency $(f)$, tidal volume, and blood pressure (BP) and recorded electrocardiograms during spontaneous breathing (14.8 \pm $0.7 \mathrm{breaths} / \mathrm{min})$ and controlled breathing at $15(0.25 \mathrm{~Hz})$ and $6(0.10 \mathrm{~Hz})$ breaths $/ \mathrm{min}$. Compared to spontaneous breathing, controlled breathing at $0.25 \mathrm{~Hz}$ showed a higher heart rate and a lower highfrequency (HF) component, an index of parasympathetic nerve activity, although the $f$ was the same. During controlled breathing at $0.10 \mathrm{~Hz}$, the ratio of the low frequency (LF) to HF components (LF/HF), an index of sympathetic nerve activity, increased greatly and HF decreased, while heart rate and BP remained almost unchanged. Thus, controlled breathing at $0.25 \mathrm{~Hz}$, which requires mental concentration, might inhibit parasympathetic nerve activity. During controlled breathing at $0.10 \mathrm{~Hz}$, LF/HF increases because some HF subcomponents are synchronized with $f$ and probably move into the LF band. This increment leads to misinterpretation of the true autonomic nervous regulation. We recommend that the respiratory pattern of participants should be evaluated before spectral HRV analysis to correctly understand changes in autonomic nervous regulation.
\end{abstract}

Keywords: autonomic nervous system; controlled breathing; heart rate variability; respiratory frequency; tidal volume Tohoku J. Exp. Med., 2014 July, 233 (3), 155-163. C 2014 Tohoku University Medical

\section{Introduction}

Since the autonomic nervous system (ANS) plays an essential role in modulating physiological conditions during physical activity, mental stress, and even sleep (Hjortskov et al. 2004; Kuo and Yang 2009; Mendonca et al. 2009), understanding this system is key to providing proper care for patients with autonomic impairment and should be useful for elucidating abnormal regulatory mechanisms of the ANS in certain diseases.

The cardiac ANS comprises sympathetic and parasympathetic nervous activities. The relative contributions of these nervous activities to the heart underlie the beat-tobeat variability of R-R intervals (RRI), which is the elapsed time between two consecutive $R$ waves on an electrocardiogram (ECG). Analysis of periodic fluctuations in heart rate, known as heart rate variability (HRV), has attracted considerable interest as a noninvasive method for quantifying alterations in cardiac autonomic regulation (Akselrod et al. 1981). Spectral analysis of HRV enables investigation of frequency-specific oscillations of heart rate fluctuation and helps decompose a series of consecutive RRI into a sum of sinusoidal functions of different amplitudes and frequencies (Moodithaya and Avadhany 2012). HRV mainly consists of two spectral components, one of low frequency (LF) and one of high frequency (HF), and it is widely accepted that the HF component of HRV reflects cardiac vagal nerve activity at the sinus node (Pomeranz et al. 1985; Berntson et al. 1993; Hayano et al. 1994; Task Force of the European Society of Cardiology the North American Society of Pacing Electrophysiology 1996). Pomeranz et al. (1985) showed atropine, a parasympathetic muscarinic blocker, practically abolished the HF component. Some studies demonstrated through spectral analysis that the HF component decreased in myocardial infarction (Lombardi et al. 1987), congestive heart failure (Axelrod et al. 1987), diabe-

Received March 13, 2014; revised and accepted May 27, 2014. Published online June 26, 2014; doi: 10.1620/tjem.233.155.

Correspondence: Ryoko Maruyama, Ph.D., Department of Health Sciences, Tohoku University Graduate School of Medicine, 2-1

Seiryo-machi, Aoba-ku, Sendai 980-8575, Japan.

e-mail: maruyama@med.tohoku.ac.jp 
tes mellitus (Lindmark et al. 2003), and aging (Fukusaki et al. 2000), and during standing compared with being in the supine position (Siebert et al. 2004). A decrease in the HF component indicates the inhibition of parasympathetic nerve activity in the heart. In other words, an alteration in cardiac vagal nerve activity probably leads to a change in the HF component.

Various pathological and physical conditions affect HRV by inducing changes in the cardiac ANS, although other factors, particularly respiratory parameters, may also affect HRV, since the HF component is associated with respiratory sinus arrhythmia (RSA), which is of respiratory origin (Novak et al. 1993; Brown et al. 1993; Pitzalis et al. 1998; Badra et al. 2001). RSA is a physiological phenomenon that is characterized by a decrease in RRI concurrent with inspiration when respiratory mechanisms in the brainstem attenuate the vagal efferent action to the heart and by an increase in RRI during expiration when the vagal efferent influence to the heart is activated (Tonhajzerova et al. 2013). Another mechanism regarding RSA is that a decrease in intrathoracic pressure that occurs during inspiratory phase causes a decrease in left ventricular stroke volume, resulting in a decrease in arterial blood pressure (BP). This decrease in BP probably leads to a decrease in RRI mediated by baroreceptor reflex (Larsen et al. 2010). Therefore, it is likely that an alteration in respiration is closely related to a change in HRV. In fact, it has been reported that the decrease in respiratory frequency $(f)$ and increase in tidal volume $\left(\mathrm{V}_{\mathrm{T}}\right)$ are positively correlated with an increase in the HF component, which suggests that the respiratory parameters themselves probably cause changes in HRV (Hirsch and Bishop 1981; Novak et al. 1993; Brown et al. 1993; Pöyhönen et al. 2004).

To avoid the respiratory impact on HRV, consciously controlled breathing has been used in experiments and clinical trials to standardize HRV measurements (Grossman et al. 1991; Piccirillo et al. 2004; Sin et al. 2010; DeBeck et al. 2010; Schaffer et al. 2013). However, it is possible that $\mathrm{HRV}$ is influenced by changes in $f$ and $\mathrm{V}_{\mathrm{T}}$ during the transition from spontaneous to consciously controlled breathing, which might lead to inaccurate estimations that deviate from the true autonomic nervous activity in the heart. In addition, the effect of consciously controlled breathing on HRV is not yet fully understood. Therefore, whether controlled breathing is required while assessing the ANS remains debated among researchers.

The aim of the present study was to clarify the effect of controlled breathing on HRV, including respiratory and circulatory parameters, and compare it with that of spontaneous breathing. We assumed that consciously controlled breathing altered HRV by inducing changes in respiratory parameters.

\section{Methods}

Subjects

Twenty young healthy male volunteers aged $22.8 \pm 0.7$ years participated in our study. Their average height, body weight, and body mass index were $172.5 \pm 1.3 \mathrm{~cm}, 62.4 \pm 1.9 \mathrm{~kg}$, and $20.9 \pm 0.5$ $\mathrm{kg} / \mathrm{m}^{2}$, respectively. All participants were non-smokers without any history of respiratory or cardiovascular disease. None of the participants routinely took medicine that affected autonomic nervous regulation or participated in sports at a competitive level. Written informed consent was obtained from all participants, and the study was approved by the Ethics Committee of the Tohoku University Graduate School of Medicine.

\section{Experimental protocol}

Data were recorded in a quiet, air-conditioned laboratory at an ambient temperature of approximately $24^{\circ} \mathrm{C}$ and humidity of approximately 40\% between 9:00 a.m. and 2:00 p.m. on a single day, considering the circadian rhythm of autonomic nervous activity (Bonnemeier et al. 2003). All volunteers were asked to refrain from drinking alcohol and caffeinated beverages for at least $12 \mathrm{~h}$ prior to data collection. They were also required to have a moderate amount of sleep the night before and not to eat for at least $2 \mathrm{~h}$ before the experiment.

The participants were seated in a comfortable chair and wore ECG electrodes and a face mask throughout the experiment. After a 5 -min rest for stabilization, they were asked to consciously control their breathing to 6 and 15 breaths $/ \min (0.10$ and $0.25 \mathrm{~Hz})$ for $5 \mathrm{~min}$ at random using a digital timer following spontaneous breathing without conscious control for $5 \mathrm{~min}$. The breathing rate of 6 breaths $/ \mathrm{min}$ was selected as it could induce dynamic changes in $f$ and $\mathrm{V}_{\mathrm{T}}$ during the transition from spontaneous to consciously controlled breathing and has been frequently used to investigate the influence of slow and deep breathing on the ANS (Hayano et al. 1994; Pitzalis et al. 1998; Ducla-Soares et al. 2007). The breathing rate of 15 breaths $/ \mathrm{min}$ is close to the mean respiratory rate in adults and has been often used to standardize measurements obtained in spectral analysis of HRV (Brown et al. 1993; Bernardi et al. 2000; Piccirillo et al. 2004). Additionally, these consciously controlled breathing rates were included within the LF band between 0.04 and $0.15 \mathrm{~Hz}$ and the HF band between 0.15 and $0.40 \mathrm{~Hz}$. All participants practiced and became accustomed to breathing at the required frequencies before the experiment (Pinna et al. 2006). Correct control of breathing was visually assessed according to the breath-by-breath $f$ displayed on the respiratory monitor.

Respiratory parameters, namely $f$ and $\mathrm{V}_{\mathrm{T}}$, were recorded continuously during the experiment by using a portable expired gas analyzer (AT-1100; Anima Co., Tokyo, Japan). Prior to data collection, the analyzer was calibrated using gas mixtures with accurately known concentrations of $\mathrm{O}_{2}$ and $\mathrm{CO}_{2}$. The validity and compatibility of the device are detailed in another report (Tajima and Ito 2006). The face mask was designed to fit comfortably without any air leakage and was fixed over the participant's mouth. Systolic and diastolic blood pressure (SBP and DBP, respectively) was measured in the right upper arm by using a digital sphygmomanometer (CITIZEN CH-308B; Tokyo, Japan). The experimental procedure is depicted in Fig. 1.

ECG data were sampled at $1,000 \mathrm{~Hz}$, digitized using an analogto-digital converter, and stored on a personal computer for subsequent analysis. Spectral analysis was performed off-line by continuous wavelet transformation using Fluclet ${ }^{\mathrm{TM}}$ (Dainippon Sumitomo Pharmaceutical Co., LTD., Osaka, Japan). LF and HF components were obtained as the area under the power spectral curve for the LF and the HF bands, respectively. In general, the HF component repre- 


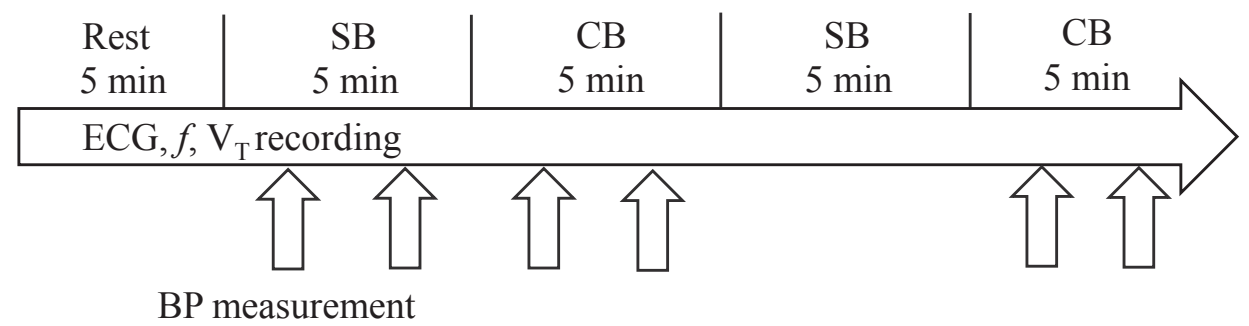

Fig. 1. Experimental protocol.

$\mathrm{SB}$, spontaneous breathing; $\mathrm{CB}$, controlled breathing; $f$, respiratory frequency; $\mathrm{V}_{\mathrm{T}}$, tidal volume; $\mathrm{BP}$, blood pressure. BP was measured at each upward arrow.

Table 1. Comparison of $\mathrm{V}_{\mathrm{T}}$, BP, and RRI between spontaneous breathing and controlled breathing at both rates.

\begin{tabular}{lccc}
\hline \multicolumn{1}{c}{ Variable } & Spontaneous breathing & Controlled breathing $(0.25 \mathrm{~Hz})$ & Controlled breathing $(0.10 \mathrm{~Hz})$ \\
\hline $\mathrm{V}_{\mathrm{T}}(\mathrm{ml})$ & $534.6 \pm 23.4$ & $594.7 \pm 29.5^{*}$ & $1,030 \pm 76.5^{* *}$ \\
$\mathrm{SBP}(\mathrm{mmHg})$ & $113.6 \pm 1.9$ & $114.6 \pm 1.5$ & $110.5 \pm 2.0$ \\
$\mathrm{DBP}(\mathrm{mmHg})$ & $64.6 \pm 1.3$ & $65.7 \pm 1.6$ & $63.6 \pm 1.6$ \\
$\mathrm{RRI}(\mathrm{msec})$ & $857.8 \pm 27.3$ & $842.5 \pm 29.4^{*}$ & $860.7 \pm 23.5$ \\
\hline
\end{tabular}

Values are presented as mean \pm standard error of the mean. ${ }^{*} p<0.05$ and $* * p<0.01$, spontaneous breathing vs. controlled breathing at $0.25 \mathrm{~Hz}$ or $0.10 \mathrm{~Hz}$ using the paired $t$-test.

$0.25 \mathrm{~Hz}=$ controlled breathing at 15 breaths $/ \mathrm{min}, 0.10 \mathrm{~Hz}=$ controlled breathing at 6 breaths $/ \mathrm{min} . \mathrm{V}_{\mathrm{T}}$, tidal volume; SBP, systolic blood pressure; DBP, diastolic blood pressure; RRI, R-R intervals.

sents parasympathetic nerve activity at the sinus node (Pomeranz et al. 1985; Berntson et al. 1993; Hayano et al. 1994; Task Force of the European Society of Cardiology the North American Society of Pacing Electrophysiology 1996), while the LF component probably reflects both sympathetic and parasympathetic modulation of heart rate (Pomeranz et al. 1985) and is strongly influenced by baroreflex activity. In our study, to estimate the autonomic nervous activity in the heart, we used the HF component as an index of cardiac vagal nerve activity and the ratio of LF to HF components (LF/HF) as an index of sympathetic nerve activity (Pagani et al. 1986).

\section{Statistical analysis}

All measurements including RRI, BP, respiratory parameters, the HF component, and LF/HF, were averaged under each breathing condition. Since no significant difference was observed between the values under the first and second spontaneous breathing conditions, we compared the values between the first spontaneous breathing condition and each controlled breathing condition using the paired $t$-test with SPSS 21.0 software (SPSS Inc., Chicago, IL, USA). Linear regression analysis was used to test the relationship between changes in respiratory parameters and the HF component. Data are presented as mean \pm standard error of the mean. A value of $p<0.05$ was considered to be statistically significant.

\section{Results}

\section{Respiratory rate}

The participants' breathing rate was $14.8 \pm 0.7$ breaths/ min during spontaneous breathing without conscious control. During consciously controlled breathing at 0.25 and $0.10 \mathrm{~Hz}$, they breathed almost correctly at $14.9 \pm 0.1$ and $6.4 \pm 0.04$ breaths $/ \mathrm{min}$, respectively. No significant differ- ence was observed between spontaneous breathing and controlled breathing at $0.25 \mathrm{~Hz}$.

\section{Changes in tidal volume during controlled breathing}

At both controlled breathing rates, $\mathrm{V}_{\mathrm{T}}$ was significantly higher than that during spontaneous breathing. During controlled breathing at $0.10 \mathrm{~Hz}$, the increase in $\mathrm{V}_{\mathrm{T}}$ was reasonable because all participants breathed slowly during the transition from spontaneous to controlled breathing. However, an unexpected increase in $\mathrm{V}_{\mathrm{T}}$ was also observed during controlled breathing at $0.25 \mathrm{~Hz}$, even though the mean respiratory rate was the same for spontaneous breathing and controlled breathing at $0.25 \mathrm{~Hz}$ (Table 1).

\section{Circulation during spontaneous breathing and controlled breathing}

No significant difference was found in the SBP and DBP between spontaneous breathing and either controlled breathing rate. However, the RRI were significantly lower during controlled breathing at $0.25 \mathrm{~Hz}$ than during spontaneous breathing (Table 1).

\section{HRV during spontaneous breathing and controlled breath- ing}

The HF component significantly decreased at both controlled breathing rates than during spontaneous breathing (Fig. 2). With regard to $\mathrm{LF} / \mathrm{HF}$, this was significantly lower during controlled breathing at $0.25 \mathrm{~Hz}$ than during spontaneous breathing. Conversely, LF/HF was considerably higher during controlled breathing at $0.10 \mathrm{~Hz}$ than at 


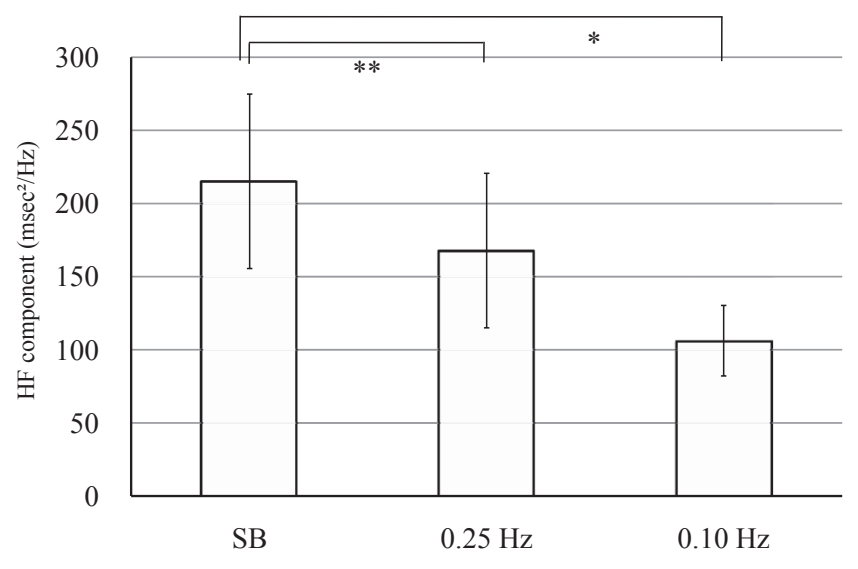

Fig. 2. Comparison of the HF component between spontaneous breathing and controlled breathing at both rates. Values are presented as mean \pm standard error of the mean. ${ }^{*} p<0.05$ and ${ }^{* *} p<0.01$, spontaneous breathing vs. controlled breathing at $0.25 \mathrm{~Hz}$ or $0.10 \mathrm{~Hz}$ using the paired $t$-test.

$\mathrm{SB}$, spontaneous breathing; $0.25 \mathrm{~Hz}=$ controlled breathing at 15 breaths $/ \mathrm{min} ; 0.10 \mathrm{~Hz}=$ controlled breathing at 6 breaths/min; HF, high frequency.

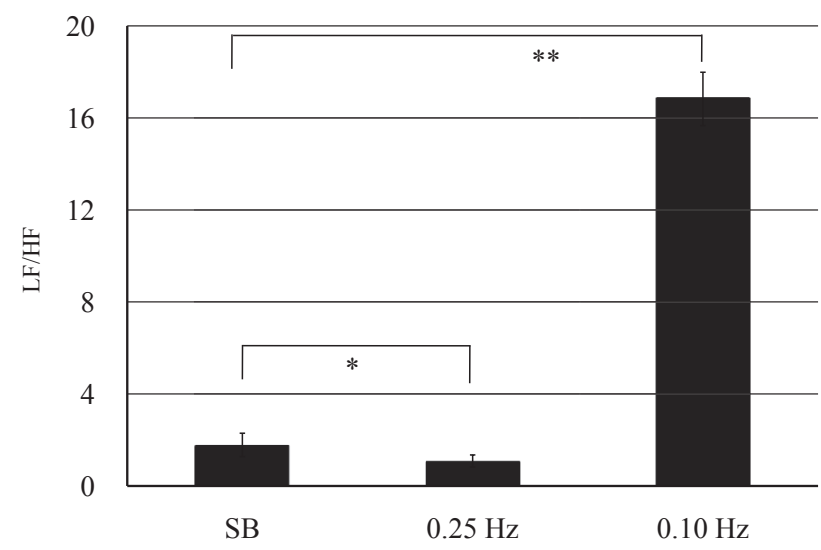

Fig. 3. Comparison of LF/HF between spontaneous breathing and controlled breathing at both rates.

Values are presented as mean \pm standard error of the mean. ${ }^{*} p<0.05$ and ${ }^{*} p<0.01$, spontaneous breathing vs. controlled breathing at $0.25 \mathrm{~Hz}$ or $0.10 \mathrm{~Hz}$ using the paired $t$-test.

$\mathrm{SB}$, spontaneous breathing; $0.25 \mathrm{~Hz}=$ controlled breathing at 15 breaths $/ \mathrm{min} ; 0.10 \mathrm{~Hz}=$ controlled breathing at 6 breaths/min; LF/HF, the ratio of the low frequency component to the high frequency component.

spontaneous breathing (Fig. 3).

Relationship between changes in respiratory parameters and the HF component during controlled breathing at 0.25 $\mathrm{Hz}$

Figs. 4 and 5 show how changes in the actual measurements of $f$ and $\mathrm{V}_{\mathrm{T}}$ affected the actual value of the HF component during the transition from spontaneous breathing to controlled breathing at $0.25 \mathrm{~Hz}$. In subjects who increased their respiratory rate during controlled breathing at $0.25 \mathrm{~Hz}$, the HF component decreased. Therefore, a significant inverse correlation exists between the change in respiratory rate and the HF component during the transition from spontaneous breathing to consciously controlled breathing at $0.25 \mathrm{~Hz}$ (Fig. 4). On the other hand, in subjects who increased their $\mathrm{V}_{\mathrm{T}}$ during controlled breathing at $0.25 \mathrm{~Hz}$, the HF component increased. Thus, the increase in $V_{T}$ from spontaneous breathing to controlled breathing at $0.25 \mathrm{~Hz}$ was correlated positively with the increase in the HF component, although this correlation was not statistically significant (Fig. 5).

\section{Discussion}

The results of the present study suggest that both controlled breathing rates affect HRV by inducing the changes in respiration, since we found that controlled breathing at $0.25 \mathrm{~Hz}$ altered the HF component and LF/HF, while the controlled breathing at $0.10 \mathrm{~Hz}$ largely affected HRV, especially $\mathrm{LF} / \mathrm{HF}$.

\section{Spontaneous respiration vs. consciously controlled respira- tion}

During controlled breathing at $0.25 \mathrm{~Hz}$, a reduction in the HF component and RRI was observed, suggesting that the conscious control of respiration leads to inhibition of vagal nerve activity in the heart, and subsequently, a decrease in RRI. The decrease in the HF component observed in this study is consistent with the findings of previous studies (Sloan et al. 1991; Patwardhan et al. 1995b; De Meersman et al. 1995). Patwardhan et al. (1995b) showed that the mean values of heart rate and BP increased, while the HF component of HRV decreased, when their participants adjusted conscious control of breathing to their own spontaneous breathing pattern. In the present study, controlled breathing at $0.25 \mathrm{~Hz}$ also caused a decline in RRI. There could be two possible explanations for this finding. The first is the changes in respiratory parameters brought about by controlled breathing, which could affect the cardiovascular system as hypocapnia due to conscious hyperventilation causes a decrease in RRI (Van De Borne et al. 2001; Debreczeni et al. 2009). In fact, we found that the $\mathrm{V}_{\mathrm{T}}$ was significantly greater during controlled breathing than during spontaneous breathing, although the mean $f$ was almost the same between both breathing conditions, and this finding supports the view that mild hyperventilation occurs during controlled breathing at $0.25 \mathrm{~Hz}$. The other possible reason could be that cortical input accompanied by the action of consciously controlled respiration induces alterations in circulatory regulation (Han et al. 1997). Controlled respiration requires mental concentration, which could tend to reduce the HF component (Sloan et al. 1991), as seen in trials where mental stress produces an increase in heart rate and BP (Pagani et al. 1991; Yoshino and Matsuoka 2005). Additionally, De Meersman et al. (1995) found that in their study, all subjects experienced discomfort and a significant loss of vagal tone through 


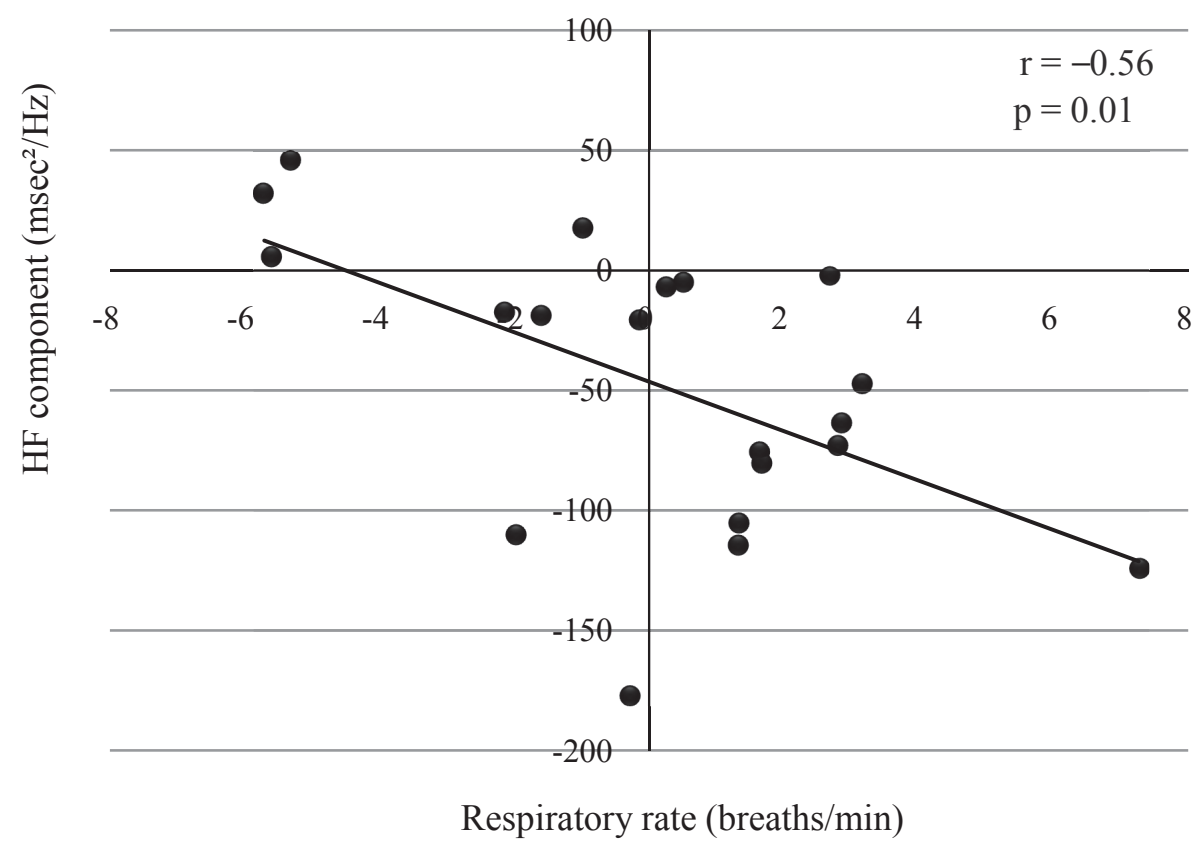

Fig. 4. Linear regression between changes in the respiratory rate and the HF component during controlled breathing at 0.25 $\mathrm{Hz}$.

Values were determined as differences in the actual measurements between controlled and spontaneous breathing. Black circles represent the individual data of 20 participants. HF, high frequency.

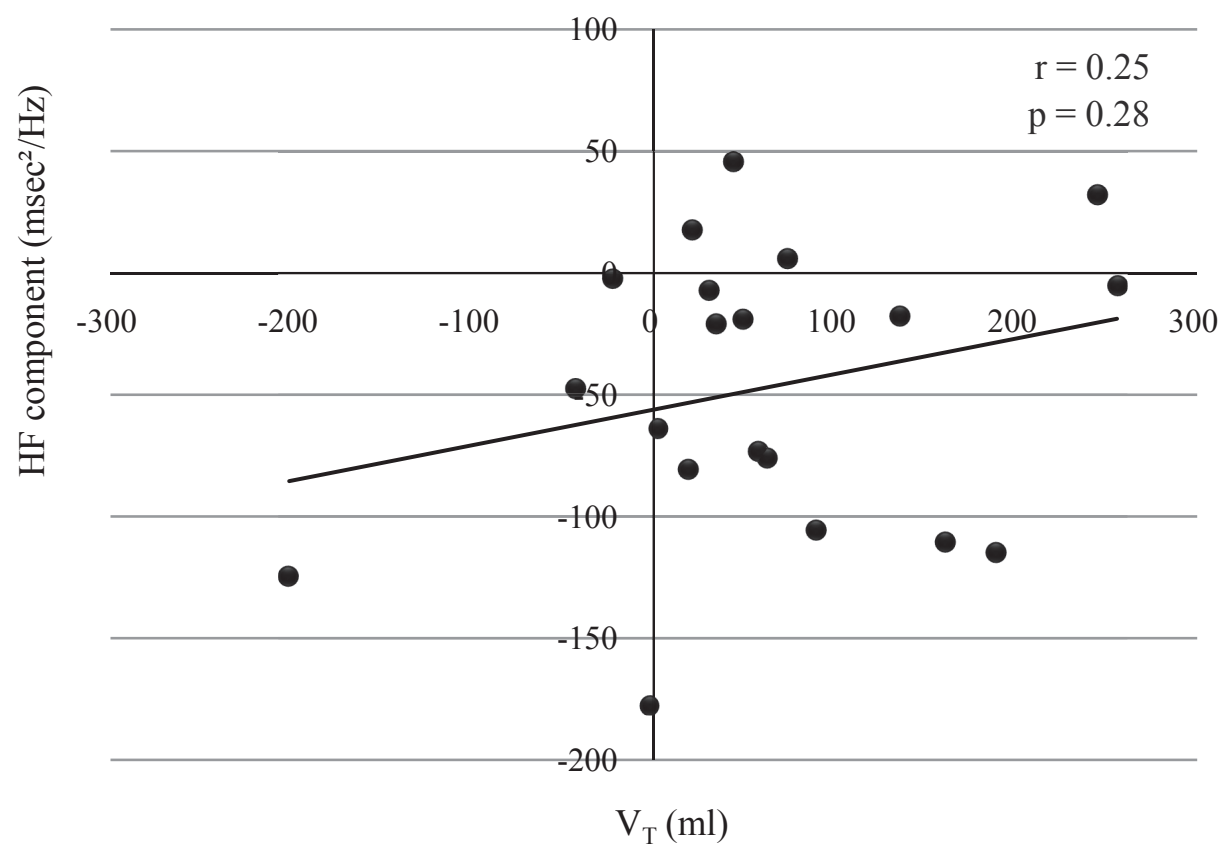

Fig. 5. Linear regression between changes in the tidal volume and the HF component during controlled breathing at $0.25 \mathrm{~Hz}$. Values were determined as differences in the actual measurements between controlled and spontaneous breathing. Black circles represent the individual data of 20 participants. $V_{T}$, tidal volume; HF, high frequency.

intervention involving adjustment of breathing rate and $\mathrm{V}_{\mathrm{T}}$. Although other findings regarding the effect of controlled breathing on HRV have found no significant difference in the HF component between spontaneous and controlled breathing (Hayano et al. 1994; Patwardhan et al. 1995a;
Bloomfield et al. 2001) or have found an increase in this component during controlled breathing compared to that during spontaneous breathing (Pagani et al. 1986; Driscoll and Dicicco 2000), the conflicting results may be attributed to different experimental procedures and parameters, 
including the controlled breathing rate and/or $\mathrm{V}_{\mathrm{T}}$, position, technique of respiration modulation, and method of HRV analysis.

Changes in respiratory parameters also have an impact on the HF component in terms of the relationship between $f$ or $\mathrm{V}_{\mathrm{T}}$ and the component as well as the inhibition of parasympathetic nerve activity at the sinoatrial node during consciously controlled breathing at $0.25 \mathrm{~Hz}$. An inverse relationship between breathing rate and the HF component has previously been reported (Hirsch and Bishop 1981; Brown et al. 1993; Hayano et al. 1994; De Meersman et al. 1995). In particular, in the present study, $f$ may have had a greater influence on the HF component than $V_{T}$ since no significant relationship was observed between $\mathrm{V}_{\mathrm{T}}$ and the HF component, and the correlation coefficient was greater for $f$ than $\mathrm{V}_{\mathrm{T}}$ (Figs. 4 and 5). These findings indicate that $\mathrm{V}_{\mathrm{T}}$ has little effect on HRV, which is supported by the fact that the effect of $\mathrm{V}_{\mathrm{T}}$ on fluctuations in RRI is negligible (Hirsch and Bishop 1981; Brown et al. 1993; Cooke et al. 1998).

In sum, the results regarding controlled breathing at $0.25 \mathrm{~Hz}$ indicate that controlled breathing with mental concentration may affect ANS function as well as respiratory and circulatory regulation, and the change in $f$ is likely an important confounding factor in the interpretation of HRV results.

\section{Respiratory frequency within the LF band}

During controlled breathing at $0.10 \mathrm{~Hz}$, a reduction in the HF component of HRV and a large increase in $\mathrm{LF} / \mathrm{HF}$ were observed, but these results may lead to the incorrect assumption of withdrawal of cardiac vagal nerve activity and activation of sympathetic nerve activity, since we showed that RRI and BP remained almost unchanged throughout the intervention. In general, provided that the above-mentioned autonomic alterations occur, the RRI decreases and BP increases. This interesting phenomenon coincides with the findings of earlier reports (Sanderson et al. 1996; Strano et al. 1998; Bernardi et al. 2000). Bernardi et al. (2000) observed that in each task accompanied with a decrease in RRI, namely, reading aloud, free talking and verbal arithmetic, the LF component increased and the HF component decreased, while the $f$ under these conditions not only decreased but also shifted into the LF band of HRV (0.04-0.15 Hz). Some HF subcomponents, namely, RSA, are synchronized with $f$ (Brown et al. 1993; Pitzalis et al. 1998) and probably move into the LF band, indicating that the increase in the LF component in some mental activities during slow respiration can be determined from the effects of slowed respiration and/or increased sympathetic nerve activity. Similarly, the slow breathing of some athletes influences the spectral indices of sympathetic activity (Strano et al. 1998). Considering the unchanged RRI and BP in our study and the findings of previous studies, the significant increase in LF/HF during controlled breathing at $0.10 \mathrm{~Hz}$ also suggests that $f$ shifts strongly into the LF band from the HF band, resulting in a relative increase in the LF component and decrease in the HF component.

Changes in the breathing pattern have been reported in several physiological situations, including exercise and sleep (Mador and Tobin 1991; Eisele et al. 1992). Moreover, RSA was found to differ depending on the spontaneous breathing period of each individual (Ben Lamine et al. 2004), since some individuality in respiration pattern exists among humans (Shea et al. 1987; Benchetrit 2000). Considering these facts, evaluation of HRV using spectral analysis necessitates assessment of the participant's respiratory style. Unless the breathing pattern is determined in subjects breathing at $0.15 \mathrm{~Hz}$ or less within the LF band, it may not be possible to accurately determine the influence of the LF component on the overall findings.

\section{Limitation}

A major limitation of our research is the effects of the face mask. In the present study, the participants wore a face mask throughout the experiment, whereby ventilation could be directly measured, since the extent to which $\mathrm{V}_{\mathrm{T}}$ changes the HF component during controlled breathing has not been determined thus far. It has previously been reported that the use of a mouthpiece and a noseclip or a face mask directly affects measurement results as the $\mathrm{V}_{\mathrm{T}}$ increases because of dead space, although the effects on minute ventilation and $f$ are not as consistent (Weissman et al. 1984; Rameckers et al. 2007). In addition, Furutani et al. (1997) observed that HRV was affected by the dead space created by the use of a face mask. In contrast, our pilot study on six healthy volunteers showed that the use of a face mask had no statistically significant effect on HRV, RRI, or BP, compared to when a mask was not used. Nonetheless, considering the findings of several studies collectively, the possibility that direct fitting with a face mask may have had an influence on HRV and cardiovascular regulation in the present study cannot be ignored.

\section{Clinical implications}

Spectral analysis of HRV in the past has provided clinically valuable information. Fukusaki et al. (2000) reported aging was associated with decreased HRV, especially the HF component, indicating attenuated parasympathetic nerve activity in the heart. In patients with severe coronary artery disease and congestive heart failure, decreased HRV was recognized as ANS impairment (Casolo et al. 1995). A decline in HRV has also been shown to be an independent predictor of fatal arrhythmic events and sudden death due to congestive heart failure (Fauchier et al. 1999). Several reports have shown ANS dysfunction among patients with diabetes mellitus (Lindmark et al. 2003), hypertension (Mussalo et al. 2001), multiple system atrophy (Kitae et al. 2001), and Parkinson disease (Ziemssen and Reichmann 2010). Additionally, the prevalence of sleep-disordered breathing may increase with age to a prevalence of approximately $20 \%$ in older patients relative to $5 \%$ to $10 \%$ in 
younger populations in The Sleep Heart Health Study (Young et al. 2002). Moreover, sleep-disordered breathing such as obstructive sleep apnea and central sleep apnea is common in patients with heart failure, and its occurrence has been reported to range from approximately $50 \%$ to $80 \%$ (Lanfranchi and Somers 2003). Further, a cohort study suggested that obstructive sleep apnea hypopnea syndrome occurred in up to $83 \%$ of patients with uncontrolled hypertension despite them taking three or more antihypertensive agents at the optimum doses (Logan et al. 2001). Sleep dysfunction including sleep apnea is also observed in patients with Parkinson disease (Diederich et al. 2005). Considering all these findings collectively, the results of our study indicate that alterations in respiratory pattern caused by sleep apnea affect HRV, and it is therefore very important to assess respiration in older patients and in patients with respiratory disturbance before evaluating autonomic regulation of the heart using spectral HRV analysis.

\section{Conclusions}

Our study involving 20 young healthy male participants showed that controlled breathing at $0.25 \mathrm{~Hz}$ changed not only HRV but also $\mathrm{V}_{\mathrm{T}}$ and RRI compared to those with spontaneous breathing without conscious control, suggesting that controlled breathing, which requires mental concentration, affects the ANS as well as respiratory and circulatory modulation. In contrast, controlled breathing at 0.10 $\mathrm{Hz}$ mostly affected LF/HF, but the RRI and BP remained almost unchanged; if only the increase in LF/HF is considered, this may be misinterpreted as activated sympathetic nerve activity. Further, our results indicate that respiratory frequency should be regarded as an important confounding factor in the interpretation of HRV findings. Despite the notion that $\mathrm{R}-\mathrm{R}$ variability is not a simple marker of vagal nerve activity but instead depends on the complex interaction between vagal and sympathetic nerve activity and respiration, little attention has been paid to respiration in many previous studies on spectral analysis of HRV. Therefore, we recommend that the respiration pattern of each participant be evaluated before spectral analysis of HRV in order to correctly understand the changes in true autonomic nervous regulation.

\section{Acknowledgments}

This work was supported in part by a Grant-in-Aid for Scientific Research (C) (18592302) from the Japan Society for the Promotion of Science.

\section{Conflict of Interest}

The authors declare no conflict of interest.

\section{References}

Akselrod, S., Gordon, D., Ubel, F.A., Shannon, D.C., Berger, A.C. \& Cohen, R.J. (1981) Power spectrum analysis of heart rate fluctuation: a quantitative probe of beat-to-beat cardiovascular control. Science, 213, 220-222.

Axelrod, S., Lishner, M., Oz, O., Bernheim, J. \& Ravid, M. (1987)
Spectral analysis of fluctuations in heart rate: an objective evaluation of autonomic nervous control in chronic renal failure. Nephron, 45, 202-206.

Badra, L.J., Cooke, W.H., Hoag, J.B., Crossman, A.A., Kuusela, T.A., Tahvanainen, K.U. \& Eckberg, D.L. (2001) Respiratory modulation of human autonomic rhythms. Am. J. Physiol. Heart Circ. Physiol., 280, H2674-H2688.

Ben Lamine, S., Calabrese, P., Perrault, H., Dinh, T.P., Eberhard, A. $\&$ Benchetrit, G. (2004) Individual differences in respiratory sinus arrhythmia. Am. J. Physiol. Heart Circ. Physiol., 286, H2305-H2312.

Benchetrit, G. (2000) Breathing pattern in humans: diversity and individuality. Respir. Physiol., 122, 123-129.

Bernardi, L., Wdowczyk-Szulc, J., Valenti, C., Castoldi, S., Passino, C., Spadacini, G. \& Sleight, P. (2000) Effects of controlled breathing, mental activity and mental stress with or without verbalization on heart rate variability. J. Am. Coll. Cardiol., 35, 1462-1469.

Berntson, G.G., Cacioppo, J.T. \& Quigley, K.S. (1993) Respiratory sinus arrhythmia: autonomic origins, physiological mechanisms, and psychophysiological implications. Psychophysiology, 30, 183-196.

Bloomfield, D.M., Magnano, A., Bigger, J.T. Jr., Rivadeneira, H., Parides, M. \& Steinman, R.C. (2001) Comparison of spontaneous vs. metronome-guided breathing on assessment of vagal modulation using RR variability. Am. J. Physiol. Heart Circ. Physiol., 280, H1145-H1150.

Bonnemeier, H., Richardt, G., Potratz, J., Wiegand, U.K., Brandes, A., Kluge, N. \& Katus, H.A. (2003) Circadian profile of cardiac autonomic nervous modulation in healthy subjects: differing effects of aging and gender on heart rate variability. J. Cardiovasc. Electrophysiol., 14, 791-799.

Brown, T.E., Beightol, L.A., Koh, J. \& Eckberg, D.L. (1993) Important influence of respiration on human R-R interval power spectra is largely ignored. J. Appl. Physiol., 75, 23102317.

Casolo, G.C., Stroder, P., Sulla, A., Chelucci, A., Freni, A. \& Zerauschek, M. (1995) Heart rate variability and functional severity of congestive heart failure secondary to coronary artery disease. Eur. Heart J., 16, 360-367.

Cooke, W.H., Cox, J.F., Diedrich, A.M., Taylor, J.A., Beightol, L.A., Ames, J.E. IV, Hoag, J.B., Seidel, H. \& Eckberg, D.L. (1998) Controlled breathing protocols probe human autonomic cardiovascular rhythms. Am. J. Physiol., 274, H709H718.

DeBeck, L.D., Petersen, S.R., Jones, K.E. \& Stickland, M.K. (2010) Heart rate variability and muscle sympathetic nerve activity response to acute stress: the effect of breathing. Am. J. Physiol. Regul. Integr. Comp. Physiol., 299, R80-R91.

Debreczeni, R., Amrein, I., Kamondi, A. \& Szirmai, I. (2009) Hypocapnia induced by involuntary hyperventilation during mental arithmetic reduces cerebral blood flow velocity. Tohoku J. Exp. Med., 217, 147-154.

De Meersman, R.E., Reisman, S.S., Daum, M., Zorowitz, R., Leifer, M. \& Findley, T. (1995) Influence of respiration on metabolic, hemodynamic, psychometric, and R-R interval power spectral parameters. Am. J. Physiol., 269, H1437H1440.

Diederich, N.J., Vaillant, M., Leischen, M., Mancuso, G., Golinval, S., Nati, R. \& Schlesser, M. (2005) Sleep apnea syndrome in Parkinson's disease. A case-control study in 49 patients. Mov. Disord., 20, 1413-1418.

Driscoll, D. \& Dicicco, G. (2000) The effects of metronome breathing on the variability of autonomic activity measurements. J. Manipulative Physiol. Ther., 23, 610-614.

Ducla-Soares, J.L., Santos-Bento, M., Laranjo, S., Andrade, A., Ducla-Soares, E., Boto, J.P., Silva-Carvalho, L. \& Rocha, I. (2007) Wavelet analysis of autonomic outflow of normal subjects on head-up tilt, cold pressor test, Valsalva manoeuvre 
and deep breathing. Exp. Physiol., 92, 677-686.

Eisele, J.H., Wuyam, B., Savourey, G., Eterradossi, J., Bittel, J.H. \& Benchetrit, G. (1992) Individuality of breathing patterns during hypoxia and exercise. J. Appl. Physiol., 72, 24462453.

Fauchier, L., Babuty, D., Cosnay, P. \& Fauchier, J.P. (1999) Prognostic value of heart rate variability for sudden death and major arrhythmic events in patients with idiopathic dilated cardiomyopathy. J. Am. Coll. Cardiol., 33, 1203-1207.

Fukusaki, C., Kawakubo, K. \& Yamamoto, Y. (2000) Assessment of the primary effect of aging on heart rate variability in humans. Clin. Auton. Res., 10, 123-130.

Furutani, Y., Shiigi, T., Nakamura, H., Nakamura, Y., Ishizaki, H., Uchiyama, K., Harada, M., Shimizu, A. \& Matsuzaki, M. (1997) Influence of the dead space induced by the face mask on the measure of heart rate variability. J. Cardiol., 29, 171-176 (in Japanese).

Grossman, P., Karemaker, J. \& Wieling, W. (1991) Prediction of tonic parasympathetic cardiac control using respiratory sinus arrhythmia: the need for respiratory control. Psychophysiology, 28, 201-216.

Han, J.N., Stegen, K., Cauberghs, M. \& Van de Woestijne, K.P. (1997) Influence of awareness of the recording of breathing on respiratory pattern in healthy humans. Eur. Respir. J., 10, 161-166.

Hayano, J., Mukai, S., Sakakibara, M., Okada, A., Takata, K. \& Fujinami, T. (1994) Effects of respiratory interval on vagal modulation of heart rate. Am. J. Physiol., 267, H33-H40.

Hirsch, J.A. \& Bishop, B. (1981) Respiratory sinus arrhythmia in humans: how breathing pattern modulates heart rate. Am. J. Physiol., 241, H620-H629.

Hjortskov, N., Rissén, D., Blangsted, A.K., Fallentin, N., Lundberg, U. \& Søgaard, K. (2004) The effect of mental stress on heart rate variability and blood pressure during computer work. Eur. J. Appl. Physiol., 92, 84-89.

Kitae, S., Murata, Y., Tachiki, N., Okazaki, M., Harada, T. \& Nakamura, S. (2001) Assessment of cardiovascular autonomic dysfunction in multiple system atrophy. Clin. Auton. Res., 11, $39-44$.

Kuo, T.B. \& Yang, C.C. (2009) Frequency domain analysis of electrooculogram and its correlation with cardiac sympathetic function. Exp. Neurol., 217, 38-45.

Lanfranchi, P.A. \& Somers, V.K. (2003) Sleep-disordered breathing in heart failure: characteristics and implications. Respir. Physiol. Neurobiol., 136, 153-165.

Larsen, P.D., Tzeng, Y.C., Sin, P.Y. \& Galletly, D.C. (2010) Respiratory sinus arrhythmia in conscious humans during spontaneous respiration. Respir. Physiol. Neurobiol., 174, 111-118.

Lindmark, S., Wiklund, U., Bjerle, P. \& Eriksson, J.W. (2003) Does the autonomic nervous system play a role in the development of insulin resistance? A study on heart rate variability in first-degree relatives of Type 2 diabetes patients and control subjects. Diabet. Med., 20, 399-405.

Logan, A.G., Perlikowski, S.M., Mente, A., Tisler, A., Tkacova, R., Niroumand, M., Leung, R.S. \& Bradley, T.D. (2001) High prevalence of unrecognized sleep apnoea in drug-resistant hypertension. J. Hypertens., 19, 2271-2277.

Lombardi, F., Sandrone, G., Pernpruner, S., Sala, R., Garimoldi, M., Cerutti, S., Baselli, G., Pagani, M. \& Malliani, A. (1987) Heart rate variability as an index of sympathovagal interaction after acute myocardial infarction. Am. J. Cardiol., 60, 12391245.

Mador, M.J. \& Tobin, M.J. (1991) Effect of alterations in mental activity on the breathing pattern in healthy subjects. Am. Rev. Respir. Dis., 144, 481-487.

Mendonca, G.V., Fernhall, B., Heffernan, K.S. \& Pereira, F.D. (2009) Spectral methods of heart rate variability analysis during dynamic exercise. Clin. Auton. Res., 19, 237-245.

Moodithaya, S. \& Avadhany, S.T. (2012) Gender differences in age-related changes in cardiac autonomic nervous function. $J$. Aging Res., 2012, 679345.

Mussalo, H., Vanninen, E., Ikäheimo, R., Laitinen, T., Laakso, M., Länsimies, E. \& Hartikainen, J. (2001) Heart rate variability and its determinants in patients with severe or mild essential hypertension. Clin. Physiol., 21, 594-604.

Novak, V., Novak, P., de Champlain, J., Le Blanc, A.R., Martin, R. \& Nadeau, R. (1993) Influence of respiration on heart rate and blood pressure fluctuations. J. Appl. Physiol., 74, 617-626

Pagani, M., Lombardi, F., Guzzetti, S., Rimoldi, O., Furlan, R., Pizzinelli, P., Sandrone, G., Malfatto, G., Dell'Orto, S., Piccaluga, E., Turiel, M., Baselli, G., Cerutti, S. \& Malliani, A. (1986) Power spectral analysis of heart rate and arterial pressure variabilities as a marker of sympatho-vagal interaction in man and conscious dog. Circ. Res., 59, 178-193.

Pagani, M., Mazzuero, G., Ferrari, A., Liberati, D., Cerutti, S., Vaitl, D., Tavazzi, L. \& Malliani, A. (1991) Sympathovagal interaction during mental stress. A study using spectral analysis of heart rate variability in healthy control subjects and patients with a prior myocardial infarction. Circulation, $\mathbf{8 3}$ (4 Suppl), II43-51.

Patwardhan, A.R., Evans, J.M., Bruce, E.N., Eckberg, D.L. \& Knapp, C.F. (1995a) Voluntary control of breathing does not alter vagal modulation of heart rate. J. Appl. Physiol., 78, 2087-2094.

Patwardhan, A.R., Vallurupalli, S., Evans, J.M., Bruce, E.N. \& Knapp, C.F. (1995b) Override of spontaneous respiratory pattern generator reduces cardiovascular parasympathetic influence. J. Appl. Physiol., 79, 1048-1054.

Piccirillo, G., Magri, D., Naso, C., di Carlo, S., MoisE, A., De Laurentis, T., Torrini, A., Matera, S. \& Nocco, M. (2004) Factors influencing heart rate variability power spectral analysis during controlled breathing in patients with chronic heart failure or hypertension and in healthy normotensive subjects. Clin. Sci., 107, 183-190.

Pinna, G.D., Maestri, R., La Rovere, M.T., Gobbi, E. \& Fanfulla, F. (2006) Effect of paced breathing on ventilatory and cardiovascular variability parameters during short-term investigations of autonomic function. Am. J. Physiol. Heart Circ. Physiol., 290, H424-H433.

Pitzalis, M.V., Mastropasqua, F., Massari, F., Passantino, A., Colombo, R., Mannarini, A., Forleo, C. \& Rizzon, P. (1998) Effect of respiratory rate on the relationships between RR interval and systolic blood pressure fluctuations: a frequencydependent phenomenon. Cardiovasc. Res., 38, 332-339.

Pomeranz, B., Macaulay, R.J., Caudill, M.A., Kutz, I., Adam, D., Gordon, D., Kilborn, K.M., Barger, A.C., Shannon, D.C., Cohen, R.J. \& Benson, H. (1985) Assessment of autonomic function in humans by heart rate spectral analysis. Am. J. Physiol., 248, H151-H153.

Pöyhönen, M., Syväoja, S., Hartikainen, J., Ruokonen, E. \& Takala, J. (2004) The effect of carbon dioxide, respiratory rate and tidal volume on human heart rate variability. Acta. Anaesthesiol. Scand., 48, 93-101.

Rameckers, H., Kohl, J. \& Boutellier, U. (2007) The influence of a mouthpiece and noseclip on breathing pattern at rest is reduced at high altitude. Respir. Physiol. Neurobiol., 156, 165-170.

Sanderson, J.E., Yeung, L.Y., Yeung, D.T., Kay, R.L., Tomlinson, B., Critchley, J.A., Woo, K.S. \& Bernardi, L. (1996) Impact of changes in respiratory frequency and posture on power spectral analysis of heart rate and systolic blood pressure variability in normal subjects and patients with heart failure. Clin. Sci., 91, 35-43.

Schaffer, T., Hensel, B., Weigand, C., Schüttler, J. \& Jeleazcov, C. (2013) Evaluation of techniques for estimating the power spectral density of RR-intervals under paced respiration conditions. J. Clin. Monit. Comput., [Epub ahead of print]. 
Shea, S.A., Walter, J., Murphy, K. \& Guz, A. (1987) Evidence for individuality of breathing patterns in resting healthy man. Respir. Physiol., 68, 331-344.

Siebert, J., Drabik, P., Lango, R. \& Szyndler, K. (2004) Stroke volume variability and heart rate power spectrum in relation to posture changes in healthy subjects. Med. Sci. Monit., 10, MT31-MT37.

Sin, P.Y., Galletly, D.C. \& Tzeng, Y.C. (2010) Influence of breathing frequency on the pattern of respiratory sinus arrhythmia and blood pressure: old questions revisited. Am. J. Physiol. Heart Circ. Physiol., 298, H1588-H1599.

Sloan, R.P., Korten, J.B. \& Myers, M.M. (1991) Components of heart rate reactivity during mental arithmetic with and without speaking. Physiol. Behav., 50, 1039-1045.

Strano, S., Lino, S., Calcagnini, G., Di Virgilio, V., Ciardo, R., Cerutti, S., Calcagnini, G. \& Caselli, G. (1998) Respiratory sinus arrhythmia and cardiovascular neural regulation in athletes. Med. Sci. Sports Exerc., 30, 215-219.

Tajima, A. \& Itoh, H. (2006) The validity of portable expired gas analyzer and its compatibility with a reference analyzer. Respir. Circ., 54, 657-662 (in Japanese).

Task Force of the European Society of Cardiology the North American Society of Pacing Electrophysiology (1996) Heart rate variability. Standards of measurement, physiological interpretation, and clinical use. Circulation, 93, 1043-1065.
Tonhajzerova, I., Mokra, D. \& Visnovcova, Z. (2013) Vagal function indexed by respiratory sinus arrhythmia and cholinergic anti-inflammatory pathway. Respir. Physiol. Neurobiol., 187, 78-81.

Van De Borne, P., Montano, N., Narkiewicz, K., Degaute, J.P., Malliani, A., Pagani, M. \& Somers, V.K. (2001) Importance of ventilation in modulating interaction between sympathetic drive and cardiovascular variability. Am. J. Physiol. Heart Circ. Physiol., 280, H722-H729.

Weissman, C., Askanazi, J., Milic-Emili, J. \& Kinney, J.M. (1984) Effect of respiratory apparatus on respiration. J. Appl. Physiol. Respir. Environ. Exerc. Physiol., 57, 475-480.

Yoshino, K. \& Matsuoka, K. (2005) Causal coherence analysis of heart rate variability and systolic blood pressure variability under mental arithmetic task load. Biol. Psychol., 69, 217-227.

Young, T., Shahar, E., Nieto, F.J., Redline, S., Newman, A.B., Gottlieb, D.J., Walsleben, J.A., Finn, L., Enright, P. \& Samet, J.M. (2002) Predictors of sleep-disordered breathing in community-dwelling adults: the Sleep Heart Health Study. Arch. Intern. Med., 162, 893-900.

Ziemssen, T. \& Reichmann, H. (2010) Cardiovascular autonomic dysfunction in Parkinson's disease. J. Neurol. Sci., 289, 74-80. 